\title{
On the Design Path of Board Writing Under the New Teaching Mode
}

\author{
Yuyun Yu \\ School of Economics and Business, Wuhan Technology and Business University, Wuhan, Hubei, China \\ 365243877@qq.com
}

\begin{abstract}
This paper analyzes the theoretical function, practical situation, unique advantages and transformation direction of traditional board writing in teaching. It suggested three design paths of possible board writing under new teaching mode: 1) to build a cognitive scaffolding; 2) to form a comprehensive learning guide; 3) to construct an interactive scroll between teacher and students.
\end{abstract}

Keywords: board writing, design path, teaching mode

\section{THE THEORETICAL FUNCTION AND PRACTICAL SITUATION OF BOARD WRITING}

Board writing has a long history in teaching field over the world. Taking China as an instance, blackboard writing began to enter classrooms since the Westernization movement of "See the West" was launched in the 1860s [1]. Theoretically, board writing in teaching has three main functions: to present the contents, to highlight the key points and to help consolidate memory. Traditionally, teachers cannot teach without board writing as an aid whereas students cannot learn without the writing as a reference. As a widespread important teaching method, board writing once played an indispensable part of classroom teaching and was paid much attention to.

However, modern education technologies are constantly innovating: in the 1970s, audio-visual methods were gradually applied to the classroom teaching; In the 1990s, multimedia equipment became popular [1]; From the original transmission projector to the physical projector; from multimedia classrooms to the latest smart classrooms, the increasing popularity and rapid update of modern educational technology constantly broaden the media of teaching information presentation. In the past decade, concepts such as "smart classroom", "digital classroom" and "future classroom" have been put forward and gradually put into practice which broaden the medium of presenting information. Modern classroom teaching no longer rely much on board writing as teachers are no longer believed to be the center of the class compared with the past. Instead, teachers are supposed to lead, to flip, to redesign the class which integrates the modern teaching technologies, so that students, the center of class, could take the most advantage. At the same time, researchers continue to explore new teaching models and update new teaching technologies whereas board writing seems to have faded out of the concern center.

Though boasted three important functions, nowadays board writing seems to have lost their power in teaching practice. It's easy to find a sharp contrast between wonderful courseware design and few or even clean board writing in teaching competitions today. Compared with the board design, multimedia design turns out to be the hot topic among teacher researchers after the teaching presentation. Courses on modern teaching technology are popular for new teachers' induction training while board writing skills are seldom mentioned. Relevant discussion on board writing by scholars are rarely seen in high-level publications. Compared with the research achievements of "micro-course design", "MOOC design" and "multimedia platform-assisted classroom teaching design", the research on blackboard writing design is a quiet corner.

Under such circumstances, some scholars pessimistically hold that "with the progress of science and technology, modern audio-visual teaching methods will finally replace the traditional board writing" [2]. In June 2019, Inner Mongolia Education published a paper titled "The Significant of the End of the Era of Board Design" (Cong Zhifang,2019). We cannot help but ask: is the era of board writing really coming to an end? 


\section{THE ADVANTAGE AND TRANSFORMATION DIRECTION OF BOARD WRITING}

Take the multimedia software PowerPoint (PPT) which is widely used in teaching today as an example: the dimension and magnitude of information transmission by PPT are several times higher than that of a board. It saves the labor and precious class time. Moreover, when combined with audio and video materials, it makes the teaching content presented in a more attractive way. As technologically superior to board writing in the three functions of "presenting contents, highlighting key points and strengthening memory", if properly designed, a PPTassisted class would be much more effective than one with traditional board writing. However, if not meticulous designed, a class relies on PPT is easily descending to a fancy information piling process as students busy glancing over slides. Software designers can make PowerPoint flashy, but they may not be able to deliver a good lecture or inspire and influence students in the long run. Whether learning really happens during the teaching and learning process is a question worth discussing. The essence and value of any technology lies in who use it to a great extent. The key factor that could make an effective class and bring long-term influences on students always depends on the teacher and his/her teaching design rather than the technology employed in class.

Refined preciseness, close demonstration and operational flexibility feature the board writing [3]. When teacher slows down the class to bother with board writing, the students would be aware that it is time to ruminate over the points or just take down notes for reviewing after-class. To some extent, the teaching-learning process is far more earnest and sincere than gobbling up page after page of PowerPoint on the big screen. And that is the unique advantage of board writing in teaching: it allows the learners to place a memory buffer in their minds so that they have time chewing and thinking in a class which is usually overwhelmed by multitudinous information.

In fact, the modern multimedia tools and traditional writing board need not be in an alternate relationship, but should be complementary to each other [4]. The design intention of multimedia tools is to free teachers from the laborious work of writing board with abundant descriptive information and present the contents in an intuitive and vivid way. Modern tools like PPT facilitate teaching but can never replace teaching activities. Today, blended teaching mode is advocated. If traditional board writing can be transformed into a new type of board writing with the aid of multimedia tools, it might be a bright way out.

\section{THE DESIGN PATH OF BOARD WRITING UNDER THE NEW TEACHING MODE}

\subsection{To Build A Cognitive Scaffolding}

The U.S. psychologist Bruner, representative of contemporary cognitive psychology, claimed that students are actively exploring in the teaching process. The main purpose of learning is not to remember the contents from the teacher and textbook, but establish the discipline system of knowledge through participating in the process. Whatever subject the teacher chooses to teach, it is important that the students understand the basic structure of each subject. This is the essential requirement in the application of knowledge, which would help students to solve problems and handle incidents outside the classroom in the future. If information acquired without a proper structure to string it together, it would be the kind of knowledge that is most easily to forget. A string of incoherent arguments has only a pitifully short life span in memory. The more a person has a sense of structure, the more he will be able to complete full and long learning episodes without fatigue. Bruner's classical treatise profoundly reveals the importance of subject structure in teaching, which requires teachers to have a holistic view, pay attention to the construction of knowledge structure and the integration of it.

Multimedia courseware has incomparable advantages over board writing in presenting verbal content and pictures. However, board writing can retain the knowledge structure of a class for a long time or even for the whole class, so as to distinguish the relationship between knowledge and guide student to explore the logic between them [5]. By contrast, the fleeting PowerPoint or on-screen board writing is difficult to do this. Therefore, one path for traditional board writing transformation is to combine the advantage of board writing with multimedia courseware to become the scaffolding of students' cognition. In practice teaching, the teacher explains the noteworthy points of each slide page, during which draws out the frame of each page on the board and forms a general framework of the whole class step by step. At the end of a class, the connection between the teaching context and the knowledge points is visualized on the blackboard. Students can see clearly and remember to the point.

The comprehensive board writing designed in this way helps students construct a cognitive structure from a panoramic view of the class content. After the whole class, the knowledge structure is completely retained on the blackboard, which is convenient for students to review, think and chew, so as to achieve the effect of "less is more". 


\subsection{To Form A Comprehensive Learning Guide}

The board writing could be a compendium of pamphlets, which is condensed and integrated from the content of this lesson. It also could also try to present the suggested learning path from the perspective of students and condense it into a leaning guide map. In the past, teachers were the authority and center of the classroom, and the main source of knowledge for students as well. Accordingly, the board writing at that time was more of detailed information or knowledge, something presented as the original reproduction of the teaching content. As modern technology has profound impact on learning process today, the goal of classroom teaching has been changed from simply impart knowledge to cultivate students' ability to generalize knowledge and acquire the essence of learning. Taking writing class as an example, the teacher could use PowerPoint or other media to present sample essays, while demonstrate on the board to present the writing framework and logical relationship shown in the sample essay step by step, and then sort out the writing skills that this class focuses on. Teachers could also use color chalk and personalized symbols to annotate key points while writing on board.

Using board writing to explain diachronic events is more effective as well. When teachers tend to use PPT to present certain event in the form of a timeline, they should manually insert shapes one by one, adjust size of each shape while paying attention to tools like color, font, images, text boxes, graphics, backgrounds, animate, etc. For a clearly and properly shown timeline slide, a nonprofessional designer as a teacher can make it in two hours with high efficiency.

What about writing the timeline on board while teaching? Most time is spent on the teaching design before the class, and in class, the design is in the teacher's mind. It's actually much more efficient to write a timeline on board and on site before the class. The process would arouse students' attention and curiosity and at the end of the class, they could review the summary on the board as thinking about the systematic logic of what they have learnt. What they have acquired is not only knowledge but also learning methods. In this way, traditional board writing intelligently integrates the conveniences of multimedia tools, and gives play to its own unique advantage to consolidate the effect of blended learning.

\subsection{To Construct An Interactive Scroll Between Teacher And Students}

To optimize the teaching effectiveness, educational researchers are constantly exploring new teaching models. In recent years, with booming "micro-class", "flipped class", "MOOCs", blended teaching mode has attracted widespread attention. It advocates that the advantages of traditional teaching and digital teaching should be combined to complement each other. The third path for transformation of traditional board writing is to use it to design interactive activities on class among teacher and students.

Like the scrolls of the opening ceremony of the Beijing Olympics in 2008, on which the leading dancer and the dancing partners are perfectly cooperating together, teachers and students are in a sense dancing together in the teaching-learning process. Teachers are the leading dancers. After a class, the footprints of teachers' guidance and learning guidance are left on the blackboard. At the same time, the board also provides a stage for students to show themselves. Teachers can try to design activities allowing teachers and students write on the board together, such as designing structured board writing while deliberately leaving blanks when writing board and so on.

Encouraging the students to go to the board and write on it, completing the writing together with the teacher enables students to change from sitting "thinking" to standing "thinking". Teachers could design structured board writing according to the teaching target, deliberately leaving blanks when writing or inviting students to write the board together. At this time, the board presents as a show stage for both the teacher and students to interact and cooperate. After writing, the teacher could not only make comments for demonstration, but also design activities like students' peer evaluation to enhance the collision of thinking and cultivate the students' critical thinking ability. In this way, the subject of writing the board and the interpersonal relationship in class are changing as well. As the class finishes, the teacher and students jointly pave a knowledge scroll as board writing not only motivate communication between teacher and students, but also promote the interaction between teaching and learning action.

\section{CONCLUSION}

There is no definite method of teaching, so is the design of board writing. What to write and how to write on the board in classroom teaching should be considered with the characteristics of the subject [7]. Subject characteristics would determine the presenting type and function of board writing. Some subjects, like math and engineering, might effectively using board for calculation and demonstration which is much more flexible and convenient than software as PPT. However, some liberal courses, take college English as an example, feature both humanistic and instrumental. The teaching contents is relatively much abstract and multifarious, sometimes difficult to present in a linear way. Moreover, compared with Chinese character, the English words are longer to write. To write out an English phrase and sense group consumes much more time. Thus, liberal courses like English are more challenging when designing what to present and how to present to students on class to a certain extent. 
However, one thing for sure is that the ultimate goal of board writing is to serve the teaching objectives. There is no need to write on the board for the sake of writing on the board, and there is also no need to completely abandon traditional tools like board writing, and revolutionary utilize high-tech devices or flashy software deliberately every where and every time in class. Methods in teaching are available, unlimited but worth selecting.

Board writing could be used to build the cognitive scaffolding, to build the comprehensive learning guide, and to construct the interactive scroll of teachers and students that complement each other. No matter what way, as long as we can combine the unique advantages of the board writing and the modern teaching tools, upgrading the traditional board writing to a new type of comprehensive board writing, and finally achieve the teaching goal of a lesson, the design would be regarded as successful. Only when teachers follow the characteristics of the subject and make elaborate plans according to the actual learning situation of students, can board writing play its unique function in teaching and achieve new effectiveness. Moreover, teachers should always bear in mind: Good board writing is not equal to successful teaching, but successful teaching is inseparable from excellent board writing.

\section{PROJECT FUND}

This paper is the stage achievement of the key projects funded by Hubei Provincial Education Science Planning in 2019--"Research on the Construction and Practice of College English 'Golden Course' Teaching Mode Based on OBE” (2019ZA10).

\section{REFERENCES}

[1] Guo Xiaoguang, (2014) Re-understanding of multimedia teaching and board-writing teaching. J. China Education Journal., 02: 71-74.

[2] Cong Zhifang, (2019) The significance of the end of the era of blackboard writing design-in-depth discussion on the relationship between teaching and learning. J. Inner Mongolia Education, 13: 29-32.

[3] Song Xiaoliang, (2014) Some Relative Advantages of Blackboard Writing vs. Multimedia -- The Necessity of Blackboard Writing in Middle School History Teaching in the Information Age. J. Education and Teaching Research., 28(02): 104$108+111$.

[4] Gao Xiaoqing, (2017) The value of traditional blackboard writing in the information age. J. Teacher., 06: 50-51.

[5] Zhang Qi, (2019) Research on integrated teaching of blackboard writing and multimedia courseware. J.
Journal of Guangxi Radio and TV University, 30(02): 64-66.

[6] Yan Guangcai, (2019) Has the traditional teaching represented by lecturing and blackboard writing been out of date? - Evaluation of effectiveness of different methods and technologies in Undergraduate classroom teaching. J. CSSCI. Educational Development Research, 39(23):1-9.

[7] Wang Xin, Gao Hongying, (2020) From the traditional blackboard to the connected blackboard: integrated thinking after the wave of electronic screens. J. Educational Informatization in China., 22: $17-21$. 